\title{
A comparative study of clinical manifestations, haematological and serological responses after experimental infection with Anaplasma phagocytophilum in two Norwegian sheep breeds
}

\author{
Snorre Stuen ${ }^{1 *}$, Lise Grøva ${ }^{2}$, Erik G Granquist ${ }^{1}$, Karin Sandstedt ${ }^{3}$, Ingrid Olesen ${ }^{4}$, Håvard Steinshamn ${ }^{2}$
}

\begin{abstract}
Background: It has been questioned if the old native Norwegian sheep breed, Old Norse Sheep (also called Norwegian Feral Sheep), normally distributed on coastal areas where ticks are abundant, is more protected against tick-borne infections than other Norwegian breeds due to a continuously high selection pressure on pasture. The aim of the present study was to test this hypothesis in an experimental infection study.

Methods: Five-months-old lambs of two Norwegian sheep breeds, Norwegian White (NW) sheep and Old Norse (ON) sheep, were experimentally infected with a $16 \mathrm{~S}$ rRNA genetic variant of Anaplasma phagocytophilum (similar to GenBank accession number M73220). The experiment was repeated for two subsequent years, 2008 and 2009, with the use of 16 lambs of each breed annually. Ten lambs of each breed were inoculated intravenously each year with $0.4 \mathrm{ml}$ A. phagocytophilum-infected blood containing approximately $0.5 \times 10^{6}$ infected neutrophils $/ \mathrm{ml}$. Six lambs of each breed were used as uninfected controls. Half of the primary inoculated lambs in each breed were re-challenged with the same infectious dose at nine (2008) and twelve (2009) weeks after the first challenge. The clinical, haematological and serological responses to A. phagocytophilum infection were compared in the two sheep breeds.
\end{abstract}

Results: The present study indicates a difference in fever response and infection rate between breeds of Norwegian sheep after experimental infection with A. phagocytophilum.

Conclusion: Although clinical response seems to be less in ON-lambs compared to NW-lambs, further studies including more animals are needed to evaluate if the ON-breed is more protected against tick-borne infections than other Norwegian breeds.

\section{Background}

Tick-borne fever (TBF) caused by the bacteria Anaplasma phagocytophilum (formerly Ehrlichia phagocytophila) is an endemic disease of sheep in tick (Ixodes ricinus) infested areas of Norway. Natural infection with A. phagocytophilum has been reported in humans and a variety of domestic and wild animal species [1]. TBF is seldom fatal, unless complicated by secondary infections. However, TBF causes immunosuppression, leaving sheep

\footnotetext{
*Correspondence: snorre.stuen@nvh.no

'Norwegian School of Veterinary Science, Department of Production Animal Clinical Sciences, Sandnes, Norway

Full list of author information is available at the end of the article
}

vulnerable to secondary infections, such as tick pyaemia caused by Staphylococcus spp. [2], and Pasteurella (Mannheimia) septicaemia [3,4]. Complications also include abortion in pregnant ewes [5], reduced milk yield in cattle [6], impaired spermatogenesis in rams [7], and reduced weight gain in lambs [8]. The infection in sheep may cause considerably animal welfare problems and has for decades been one of the main scourges for the Norwegian sheep industry [8].

A serological survey in sheep indicated that $A$. phagocytophilum infection is widespread along the coast of southern Norway. However, clinical TBF was only diagnosed in half of these seropositive sheep flocks [9].

\section{C) Biomed Central}


The reason for this diagnostic deficit may be attributed to the existence of genetic variants of the agent causing different clinical symptoms and immunological reactions $[2,10]$. Based on a $16 \mathrm{~S}$ rRNA gene sequence study, it has recently been shown that genotypes of $A$. phagocytophilum may co-exist in the same sheep flock and even in the same animal [11]. The geographical distribution of these variants is however unknown.

The management of sheep flocks may vary considerably in Norway. While the dominant Norwegian sheep breed, Norwegian White (NW) sheep, are normally housed indoors during the winter season and treated regularly against ticks and gastro-intestinal parasites, the Old Norse (ON) sheep breed can be on pasture the whole year around with limited parasitic treatment [12]. A British study indicated earlier, that there may be a difference in breed susceptibility to A. phagocytophilum infection [13]. Based on a continuous high selection pressure and possible also breed differences, it has been hypothesized that the ON-breed is more protected against tick-borne infections than other Norwegian breeds. The aim of the present study was therefore to test this hypothesis by experimental infection, to compare the clinical, haematological and serological responses to A. phagocytophilum infection in two Norwegian sheep breeds.

\section{Materials and methods}

\section{Source of Anaplasma phagocytophilum and DNA sequencing}

Blood samples were collected from a flock of Norwegian sheep known to be infected with A. phagocytophilum. Based on partial sequencing of the $16 \mathrm{~S}$ rRNA gene, a variant of $A$. phagocytophilum was found in one lamb, similar to GenBank accession number M73220 [11]. Both EDTA and heparinised blood samples were taken from the infected lamb. The EDTA blood samples were used to measure haematological values and to prepare blood smears. The absolute number of infected cells per unit volume was determined by multiplying the total number of neutrophils per unit volume by the percentage of infected neutrophils counted on a May-Grünwald Giemsa stained blood smear. The heparinised blood was stored at $-70^{\circ} \mathrm{C}$ in $5 \mathrm{ml}$ aliquots with $10 \%$ dimethyl sulphoxide (DMSO) as cryoprotectant without any propagation in cell culture or sequence passage through other sheep.

\section{Animals, experimental design, and haematology}

A total number of 64 lambs, 5 months old, were used in this trial, 32 lambs of the NW-breed and 32 of the ONbreed. The experiment was approved by the National Animal Research Authority (Norway). The study was conducted for two following years, 2008 and 2009, with the yearly use of 16 lambs of each breed. The ON- lambs came from two different sheep herds in Rogaland county, lambs from one herd were used each year, while all NW-lambs belonged to the experimental sheep flock at the Department of Production Animal Clinical Sciences. All ON-lambs were adapted and housed at the department three to four months before start of the experimental period. None of the lambs had previously been exposed to pasture with I. ricinus and were kept indoors during the whole experimental period of four to five months. The lambs of each breed were grouped in infected and controls, according to equal distribution of sex and mean live weight. Ten lambs of each breed were inoculated intravenously (day 0 ) with $0.4 \mathrm{ml}$ of the above mentioned DMSO-stabilate of A. phagocytophilum using one aliquot for each breed. The infectious blood contained approximately $0.5 \times 10^{6}$ infected neutrophilic granulocytes/ml. Six lambs in each group were left as uninfected controls. Nine weeks (2008) and twelve weeks (2009) after the primary inoculation, five of the earlier inoculated lambs of each breed were selected by random sampling and re-challenged with the same infectious dose of the homologous variant.

The lambs were observed at least twice a day. Rectal temperature was measured daily in all lambs throughout the experiment. The incubation period was defined as the period between inoculation and the first day of fever $\left(\geq 40.0^{\circ} \mathrm{C}\right)$, and the duration of fever was recorded as the number of days with elevated body temperature $\left(\geq 40.0^{\circ} \mathrm{C}\right)$. The magnitude of fever of each lamb was estimated from the area of plots of daily temperature on $5 \mathrm{~mm}$ grids and calculated according to the Trapezium Rule [14]. For this purpose $40^{\circ} \mathrm{C}$ represented the baseline.

Daily EDTA blood samples were collected during the fever period, and on a weekly basis after the fever had subsided. In addition, EDTA blood samples were later collected from individual lambs when intermittent rectal temperatures above $40.0^{\circ} \mathrm{C}$ were recorded. Total and differential leucocyte counts were determined electronically $\left(\right.$ ADVIA ${ }^{\circledR}$, Bayer) and blood smears were prepared and stained with May-Grünwald Giemsa. Four hundred neutrophils were examined on each smear by light microscopy, and the number of cells containing Anaplasma inclusions was recorded. The infection rate (percentage of infected neutrophils) was calculated. The body weight of all lambs was measured weekly, during the whole experimental period. The average live weights $( \pm$ SD) of the lambs at the start of the experiment were $52.8 \pm$ 6.86 (NW-2008), $44.9 \pm 6.10$ (NW-2009), $28.8 \pm 4.10$ (ON-2008), and $21.3 \pm 3.44$ (ON-2009), respectively.

\section{Extraction of DNA and real time PCR for the identification} of A. phagocytophilum positive samples, targeting msp2 (p44)

In order to investigate A. phagocytophilum infection of non-reactive lambs, the ON-lambs (2009) were analysed 
for Anaplasma -DNA by PCR [15]. Briefly, an automated isolation procedure based on magnetic bead technology was performed by the application of the MagNA Pure LC instrument (Roche) and the MagNA Pure LC DNA Isolation Kit I Blood Cells High Performance (Roche). EDTA blood samples from the inoculated animals were thawed at room temperature and $200 \mu \mathrm{l}$ blood was transferred to the DNA isolation procedure according to the instruction manual (Roche). The isolated DNA was eluted with $100 \mu \mathrm{l}$ low salt buffer and stored at $-20^{\circ} \mathrm{C}$ awaiting PCR analysis. The concentration of DNA in each sample was determined by $\mathrm{OD}_{260}$ spectrophotometry (GeneQuant II, Pharmacia Biotech, Cambridge, UK). The samples were diluted 1:100 before PCR analysis.

The primers were Ap MSP2 252 5' ACAGTCCAGCGTTTAGCAAGA and Ap MSP2 459 5' CACCACCAATACCATAACCA, amplifying a product of $208 \mathrm{bp}$ at the $\mathrm{N}$-terminal hyper variable region of the msp2(p44) expression site. The primers were manufactured by TIB Molbiol (Germany). A Light Cycler 480 instrument (Roche) was used for the real-time PCR analysis. A total of 96 well white plates were loaded with a reaction mix consisting of $0.5 \mu \mathrm{l}(5 \mu \mathrm{M})$ ApMSP2 252 primer, $0.5 \mu \mathrm{l}(5 \mu \mathrm{M})$ ApMSP2 459 primer, $1.5 \mu \mathrm{l}$ RNAse free $\mathrm{H}_{2} \mathrm{O}, 5 \mu$ l LightCycler 480 DNA SYBR Green I Master and $2.5 \mu \mathrm{l}$ sample. Plates were sealed by sealing foil and centrifuged at $1200 \mathrm{rpm}$ for two minutes. Samples and non-template controls were run in duplicates on each plate. The $\mathrm{C}_{\mathrm{q}}$ values (quantification cycle) were determined by the $2^{\text {nd }}$ derivative maximum method and verified by melting point analysis (Tm) [15].

\section{Serology}

Sera were collected at days $0,7,14,21,28,42$, and 63 (only first challenge) after each inoculation and analysed using an indirect immunofluorescence antibody assay (IFA) to determine the antibody titre to Ehrlichia equi $[9,16]$. Briefly, two-fold dilutions of sera were added to slides precoated with A. phagocytophilum (formerly E. equi) antigen (Protatec, St. Paul, Minn.). Bound antibodies were visualized by fluorescein-isothiocyanate (FITC)-conjugated rabbit-anti-sheep immunoglobulin (Cappel, Organon Teknika, West Chester, PA). Sera were screened for antibodies at dilution 1:40. If positive, the serum was further diluted and retested. A titre of $1.6\left(\log _{10}\right.$ reciprocal of $\left.1: 40\right)$ or more was regarded positive.

\section{Statistics}

Statistical calculations were done using Statistix, version 4.0 (Analytical Software), and a two-sample $t$ test was used to analyse clinical, haematological and serological variables. A $P$ value of $<0.05$ was considered significant.

\section{Results}

Clinical parameters, haematology, PCR-detection and serology

In general, a one to two days period with reduced appetite was observed in the NW-lambs infected with A. phagocytophilum, while infected ON-lambs showed no signs of clinical illness.

In 2008, all inoculated lambs from both groups developed fever. Significant differences in duration of fever and magnitude of fever were recorded between the two sheep breeds (Table 1). In addition, infection rate was significantly different on days 3, 6, 7 and 8 (Table 2). However, no significant difference was observed in the serological response for the first 63 days (Figure 1). Recurrent fever periods of one to two days duration, were observed in five $(\mathrm{NW})$ and four $(\mathrm{ON})$ lambs, respectively.

After re-challenge on day 63 (2008), clinical signs were not observed, and only one lamb of each breed reacted with a detectable infection rate (Table 3 ). No significant difference in the antibody titre was observed in the challenged and unchallenged lambs in either of the two breeds (data not shown).

In contrast, only seven of the infected ON-lambs in 2009 reacted with fever after the primary inoculation (Table 1). The most remarkable finding was that the incubation time in these seven $\mathrm{ON}$-lambs varied from six to thirteen days (mean \pm SD: $9.6 \pm 2.44$ ) and the fever period lasted for one to ten days (mean \pm SD: $5.4 \pm 3.11$ ). Significant differences in incubation period, maximum temperature, magnitude of fever and weight gain were recorded between the two sheep breeds (Table 1). Two infected ON-lambs had fever for one day, with a max. temperature of $40.0^{\circ} \mathrm{C}$ and $40.4^{\circ} \mathrm{C}$, respectively. The infection rate was displaced by several days and therefore difficult to compare from day to day (Table 3). However, the max. infection rate was not significantly different (Table 1). In addition, no significant difference between the two breeds was observed in the serological reaction for the first 84 days, except for day $14(\mathrm{p}<0.05)$ (Figure 2).

The three ON-lambs that did not show any clinical reaction after $A$. phagocytophilum inoculation were also found negative by blood smear examination and serology. In addition, real time PCR for identification of $A$. phagocytophilum positive samples was negative in these three lambs on days 3-15 (Table 4). In the infected ON-lambs, Anaplasma-DNA was detected as early as five days before inclusions were observed by blood smear microscopy. Recurrent fever periods of one to two days duration, were observed in two lambs of each breed, respectively.

After re-challenge on day 84, all five ON-lambs reacted with a clinical response. One of the lambs, which did not react after the first inoculation, now responded with a typical $\mathrm{TBF}$ - infection, i.e. incubation 
Table 1 Mean and standard deviation ( \pm SD) of different clinical variables in 5-month-old lambs of two Norwegian Sheep breeds, Norwegian White (NW) and Old Norse (ON), respectively, infected with one variant of A. phagocytophilum

\begin{tabular}{|c|c|c|c|c|c|c|}
\hline & \multicolumn{3}{|c|}{2008} & \multicolumn{3}{|c|}{2009} \\
\hline & NW & ON & P-value & NW & $\mathrm{ON}^{\#}$ & P-value \\
\hline Incubation period (days) & $3.0 \pm 0.0$ & $2.9 \pm 0.3$ & ns & $3.0 \pm 0.0$ & $9.6 \pm 2.4$ & $p<0.0001$ \\
\hline Max. temp. $\left({ }^{\circ} \mathrm{C}\right)$ & $41.87 \pm 0.18$ & $41.64 \pm 0.11$ & ns & $41.86 \pm 0.13$ & $40.96 \pm 0.54$ & $p<0.001$ \\
\hline Duration of fever (days) & $8.9 \pm 2.77$ & $5.6 \pm 1.02$ & $p<0.01$ & $8.0 \pm 3.07$ & $5.4 \pm 3.11$ & Ns \\
\hline Magnitude of fever $\left(\mathrm{mm}^{2}\right)$ & $912 \pm 158$ & $503 \pm 89$ & $p<0.001$ & $737 \pm 231$ & $275 \pm 174$ & $p<0.001$ \\
\hline Nadir of neutropenia $\left(<0.7 \times 10^{9}\right.$ litre $\left.^{-1}\right)$ & $0.22 \pm 0.06$ & $0.22 \pm 0.08$ & ns & $0.26 \pm 0.10$ & $0.28 \pm 0.15$ & Ns \\
\hline Duration of neutropenia (days) & $9.1 \pm 2.38$ & $10.1 \pm 2.21$ & ns & $6.7 \pm 2.24$ & $5.7 \pm 2.49$ & Ns \\
\hline Max. infection rate (\%) & $49.0 \pm 3.46$ & $44.6 \pm 5.66$ & ns & $52.9 \pm 1.79$ & $46.6 \pm 9.76$ & Ns \\
\hline Weight loss (\%) ${ }^{a}$ & $-10.7 \pm 3.21$ & $-9.5 \pm 4.63$ & ns & $-9.6 \pm 2.81$ & $1.4 \pm 4.20$ & $p<0.001$ \\
\hline
\end{tabular}

${ }^{a}$ weight loss was measured one week after inoculation; ns - not significant.

\# only seven lambs were infected.

The study was performed in two subsequent years, 2008 and 2009, respectively. Ten lambs in each group were inoculated. A two-sample $t$ test was used for statistical analysis.

period: 3 days, max. temperature: $40.9^{\circ} \mathrm{C}$; magnitude of fever: $273 \mathrm{~mm}^{2}$ and duration of fever: 7 days. In addition, blood smears displayed cytoplasmic inclusions (max. infection rate: 60\%), duration of neutropenia (7 days) and a serological response (titre value on day 98 : $1 / 1280$ ). All the other four ON-lambs also reacted with fever of 1-2 days duration, cytoplasmic inclusions (max. infection rate: 6-56\%), and neutropenia (duration: 3-5 days) after re-challenge. A significant increase in antibody titre $(\mathrm{p}<0.05)$ was observed in the re-challenged lambs compared with the unchallenged lambs on days 98, 105 and 112, respectively (data not shown). In contrast, the five NW-lambs that were re-challenged on day 84 , did not react with a clinical response, cytoplasmic inclusions or a titre increase (Table 3, Figure 2). Clinical symptoms, haematological reaction or seroconversion were not detected in the control lambs during the experimental period.

Comparison of results from 2008 and 2009, showed no difference in clinical signs or haematological reaction between the NW-lambs (two-sample $t$ test). The infection rate was significantly different only on days 3 and 4 $(p<0.001)$. However, significant differences were observed in the antibody titres on days $14,21,28,42$ and $63(\mathrm{p}<0.001)$. Significant differences in the antibody responses were also observed between the ONlambs in 2008 and 2009, i.e. on days 14, 21, 28, 42 and 63 ( $\mathrm{p}<0.01)$, respectively. In addition, variation in clini$\mathrm{cal}$ and haematological responses and infection rates were observed within the ON-breed, such as in the maximum temperature $(\mathrm{p}<0.05)$, magnitude of fever $(\mathrm{p}$ $<0.01)$, duration of neutropenia $(\mathrm{p}<0.01)$ and weight gain $(\mathrm{p}<0.001)$ (two-sample $t$ test).

\section{Weight gain}

In 2008 , the mean daily weight gains $( \pm$ SD) for the first nine weeks in the infected and control lambs were $180 \pm$ $21.2 \mathrm{~g} / \mathrm{d}$ (NW-infected), $204 \pm 35.9 \mathrm{~g} / \mathrm{d}$ (NW-control), $155 \pm 47.8 \mathrm{~g} / \mathrm{d}$ (ON-infected), and $164 \pm 44.5 \mathrm{~g} / \mathrm{d}$ (ON-control), respectively. No significant differences between the infected and control lambs within each breed were observed.

Similarly, the mean daily weight gains $( \pm \mathrm{SD})$ for the first twelve weeks in the infected and control lambs in 2009 were $137 \pm 30.0 \mathrm{~g} / \mathrm{d}$ (NW-infected), $165 \pm 16.1$ (NW-control), $78.1 \pm 29.0 \mathrm{~g} / \mathrm{d}(\mathrm{ON}$-infected), and $105 \pm 18.9$ (ON-control),

Table 2 Mean percentage of infected neutrophils observed in groups of ten lambs $\$$ of two different breeds of Norwegian sheep, Norwegian White (NW) and Old Norse (ON), respectively, inoculated with one variant of $A$. phagocytophilum

\begin{tabular}{|c|c|c|c|c|c|c|c|c|c|c|c|}
\hline \multicolumn{4}{|c|}{ Sheep breeds } & \multicolumn{8}{|c|}{ Days after inoculation/challenge } \\
\hline & 3 & 4 & 5 & 6 & 7 & 8 & 10 & 11 & 12 & 13 & 17 \\
\hline NW - 2008 & $43.2^{\#}$ & 45.4 & 36.4 & $41.2^{\#}$ & $37.8^{\# \#}$ & $32.0^{\#}$ & 22.6 & 3.3 & $<1$ & - & - \\
\hline ON - 2008 & 35.1 & 44.4 & 35.8 & 32.8 & 25.0 & 11.7 & 2.1 & 1.9 & $<1$ & & \\
\hline NW - 2009 & 7.9 & 57.4 & 45.2 & 39.8 & 35.2 & 27.6 & 3.3 & $<1$ & - & & \\
\hline ON - 2009 & - & - & - & - & $13.0^{\mathrm{a}}$ & $26.0^{\mathrm{b}}$ & $47.5^{\mathrm{b}}$ & $24.5^{c}$ & $32.1^{d}$ & $22.9^{d}$ & $3.8^{\mathrm{b}}$ \\
\hline
\end{tabular}

\footnotetext{
$\$$ only seven ON-2009 lambs were infected.
}

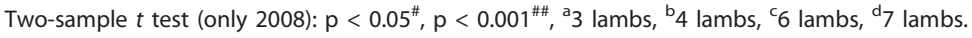

The study was performed in two subsequent years, 2008 and 2009, respectively. 


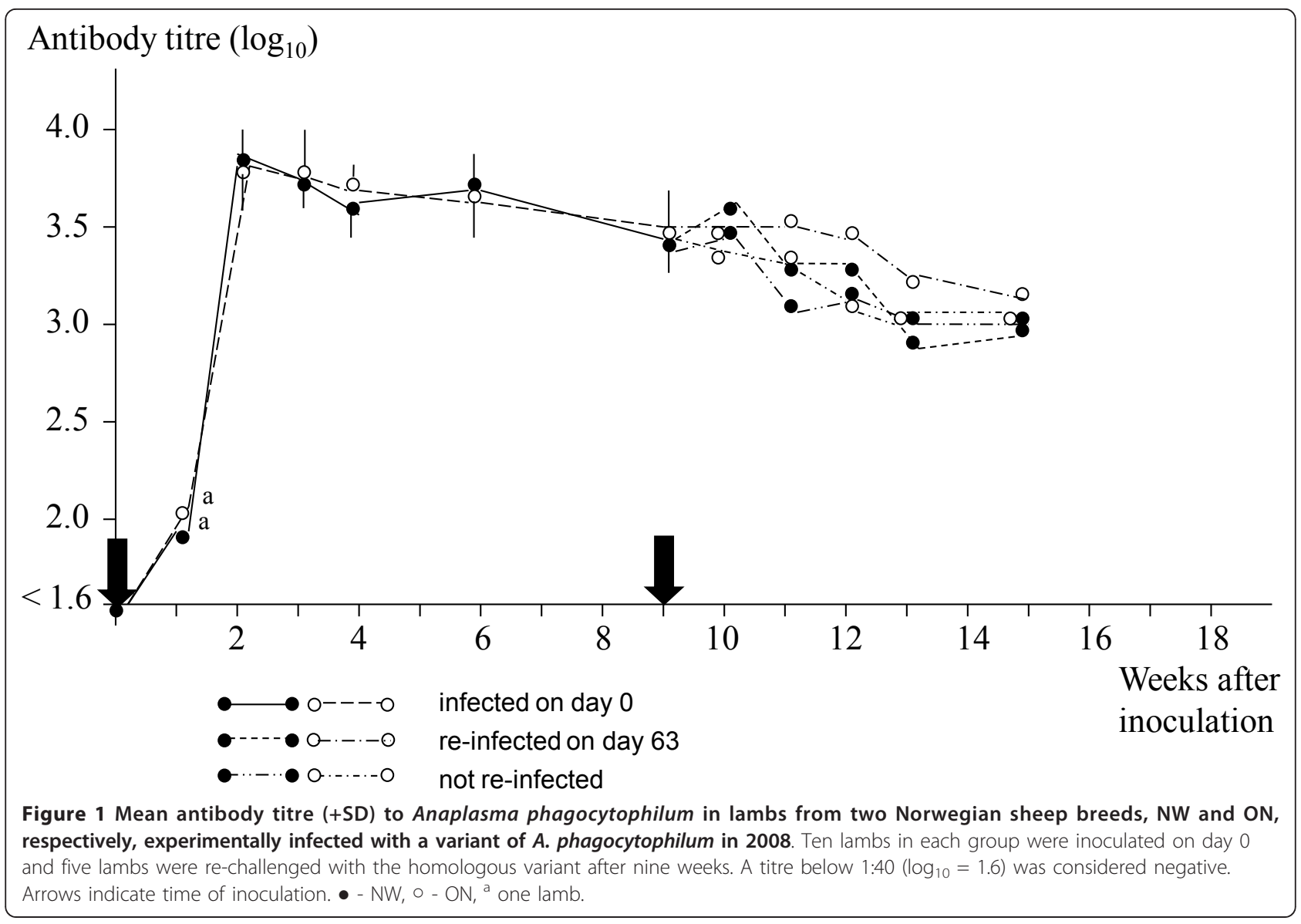

respectively. No significant differences between the infected and control lambs within each breed were observed.

\section{Discussion}

In the present study, only a limited number of animals of each breed were included. Earlier experimental studies in $\mathrm{NW}$-lambs indicate a variation in clinical, serological and haematological reactions to an $A$. phagocytophilum infection [8]. In order to evaluate the susceptibility in outbred sheep breeds, more animals should have been included. In addition, the study should have been conducted within

Table 3 Mean percentage of infected neutrophils observed in groups of five lambs inoculated with one variant of $A$. phagocytophilum nine weeks (NW/ON-2008) and twelve weeks (NW/ON-2009) after the first inoculation, respectively

\begin{tabular}{lllllllll}
\hline Sheep breeds & \multicolumn{8}{c}{ Days after inoculation/challenge } \\
& $\mathbf{3}$ & $\mathbf{4}$ & $\mathbf{5}$ & $\mathbf{6}$ & $\mathbf{7}$ & $\mathbf{8}$ & $\mathbf{1 0}$ & $\mathbf{1 1}$ \\
\hline $\mathrm{NW}-2008$ & - & $<1$ & - & - & - & - & - & - \\
$\mathrm{NW}-2009$ & - & - & - & - & - & - & - & - \\
$\mathrm{ON}-2008$ & - & - & $10^{\mathrm{a}}$ & $24^{\mathrm{a}}$ & $16^{\mathrm{a}}$ & $1^{\mathrm{a}}$ & - & - \\
$\mathrm{ON}-2009$ & $13.5^{\mathrm{b}}$ & 30.6 & 25.4 & 20.8 & $11.5^{\mathrm{c}}$ & $5.5^{\mathrm{b}}$ & $<1^{\mathrm{a}}$ & - \\
\hline
\end{tabular}

a 1 lamb, ${ }^{\text {b }} 2$ lambs, ${ }^{c} 4$ lambs. one year to exclude annual variation in experimental conditions. However, due to limited number of lambs available, housing facilities and other practical reasons these criteria were difficult to fulfil.

Significant differences in the clinical reaction and infection rate to a primary $A$. phagocytophilum infection were detected in the two sheep breeds. In 2008, no differences in the haematological and the serological reaction were observed. In contrast, marked differences were observed in 2009, where seven ON-lambs reacted with a prolonged incubation period and no evidence of clinical response in three lambs. Breed differences in response to $A$. phagocytophilum have, as mentioned earlier, been shown among British sheep breeds. Blackface sheep reacted less severely to tick-borne fever than other breeds and their crosses, however this seems not entirely attributable to past ancestral exposure to the pathogen [13]. The reason and implication of these breed differences need further elucidation.

A significant difference in the antibody titre response was recorded between the two years. This may be due to different batches of antigen used, since the sensitivity of the IFA-test may vary between batches (Sandstedt K, personal information). The sensitivity of the present 


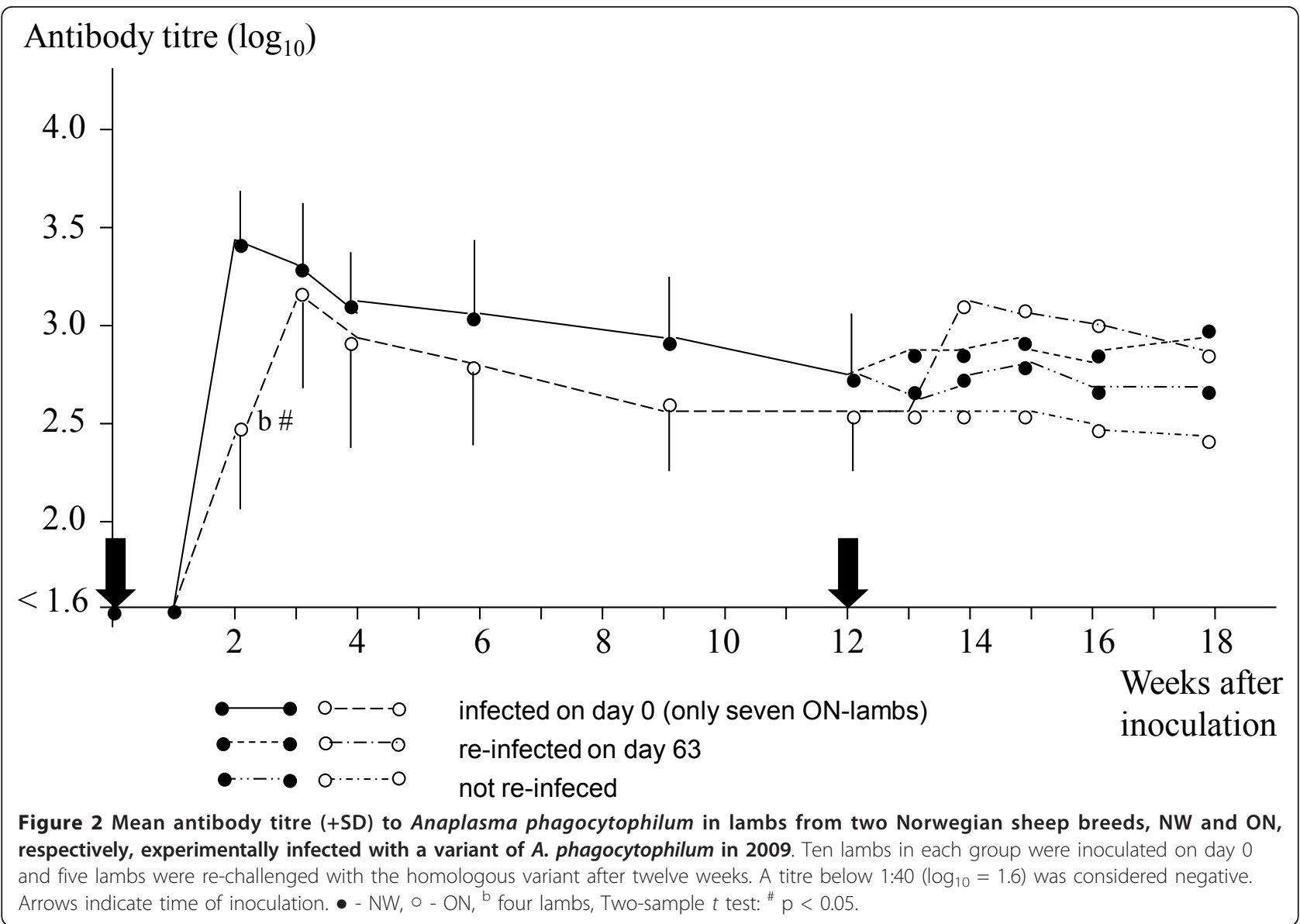

antibody test may have been increased by use of a more proper antigen, i.e. an ovine variant of the bacterium. Strong serological cross-reactions between all members of the A. phagocytophilum group have been reported, but the titre response to a heterologous variant is

Table 4 Detection of $A$. phagocytophilum infection by real-time PCR, targeting msp-2(p44) in ON-lambs

\begin{tabular}{ccccccc}
\hline ON-lambs 2009 & Day 0 & Day 3 & Day 5 & Day7 & Day10 & Day15 \\
\hline 1 & - & - & + & + & $+^{\#}$ & $+^{\#}$ \\
2 & - & - & - & nd & + & $+^{\#}$ \\
3 & - & - & + & $+^{\#}$ & $+^{\#}$ & $+^{\#}$ \\
4 & - & - & - & - & - & - \\
5 & - & - & - & nd & $+^{\#}$ & $+^{\#}$ \\
6 & - & - & - & - & - & - \\
7 & - & - & + & + & $+^{\#}$ & $+^{\#}$ \\
8 & - & - & - & - & - & $+^{\#}$ \\
$9^{\# \#}$ & - & - & - & - & - & - \\
10 & - & - & - & $+^{\#}$ & $+^{\#}$ & $+^{\#}$
\end{tabular}

- negative, + positive, nd - not done.

\# positive by light microscopy.

\#\# this lamb became infected with $A$. phagocytophilum only after re-challenge on day 84.

All lambs were inoculated experimentally with $A$. phagocytophilum infected blood on day 0 . normally less than against a homologous variant [17]. Unfortunately, E. equi was the only antigen available for use in the present study.

In contrast to NW-lambs, marked differences in clinical and haematological reactions were observed between years in the ON-lambs. The reason for these differences among ON-lambs is unknown. The animals were from two different geographical areas with no direct relationship, and the lambs had been adapted to the same experimental conditions for several months. In addition, earlier studies indicate that the individual diversity is not significantly different within the two sheep breeds involved [18].

In 2009, seven ON-lambs reacted with a long incubation period, a low maximum temperature and a short duration of fever [8]. These reactions may indicate an innate resistance to A. phagocytophilum. However, an innate immune response in infected lambs may be inefficient since $A$. phagocytophilum have lost all genes for synthesis of LPS and most genes for biosynthesis of peptidoglycans $[19,20]$.

Earlier studies indicate that the amplitude of clinical and haematological reaction is independent of the dose of the A. phagocytophilum inoculum, however, the incubation period may be longer with a low infection dose. 
As little as one A. phagocytophilum infected cell is enough to transmit the infection [21]. In the present study, the inoculation dose was approximately $0.2 \times 10^{6}$ infected neutrophils, which should be more than sufficient to create a clinical reaction. However, reduction of the infectious dose in the aliquot used during freezing and thawing cannot be excluded.

Most of the inoculated blood used in 2009 must have been infectious. However, if a small infection dose in the thawed aliquot was divided into ten infectious doses, some of these batches may have lacked infectivity. This statement is supported by the fact that AnaplasmaDNA was not detected in the three non-responsive lambs during the first fourteen days. The detection threshold of real-time PCR used was 10 copies of DNA [15]. These three lambs were also confirmed seronegative. In addition, when one of these three lambs was challenged on day 84 , it was fully susceptible to the infection. Further studies are needed to elucidate the reason for the delayed onset of clinical reactions in $\mathrm{ON}$ lambs, experimentally infected with A. phagocytophilum.

In the present study, the daily weight gain in lambs varied between the two years. This variation may be due to the quality of the roughage involved. Unfortunately, the quality of the silage used was not measured. The daily weight gain between the infected and non-infected animals of each breed was not significantly different. One study indicates that an early $A$. phagocytophilum infection will have a negative effect on the autumn live weight of lambs [22]. However, in that study the infected lambs were grazing on pasture, while in the present trial the experimental lambs were housed indoors under favourable environmental conditions.

Resistance to experimental re-infections rises with increasing frequency of challenge [23]. Earlier experimental studies have shown that the immunity after primary $A$. phagocytophilum infection varies and that sheep may resist homologous challenge for a period from a few months to more than one year [2,24-26]. In the present study, only the ON-lambs (2009) reacted with clinical symptoms, detectable infection rate and an increase in antibody titre after re-infection, indicating that they were not fully protected after the primary infection. The implications of relapses of clinical symptoms and bacteraemia during the persistent period are unknown. The effects of re-infections are usually less severe than the primary reaction. However, it depends on the variants of A. phagocytophilum involved [10].

Earlier investigations have shown that lambs are susceptible to secondary infections, especially in the bacteraemic and neutropenic periods of TBF [14,27-29]. In the present study, only the rate of bacteraemia is different between the two breeds. To evaluate if A. phagocytophilum infected $\mathrm{ON}$-lambs are more resistant to other infectious agents compared to NW-lambs needs further investigation, since factors such as management and other external stress factors may be important to the outcome of infection [30].

\section{Conclusion}

The present results indicate a difference in fever response and infection rate between breeds of Norwegian sheep after experimental infection with A. phagocytophilum. Whether these differences are due to genetic resistance that can be implemented in a breeding programme to increase the resistance against TBF, needs further exploration. However, studies including more animals are needed to evaluate if the ON-breed is more protected against tick-borne infections than the NW-breed. In addition, analyses of diseased and fatal cases of TBF must be performed in order to elucidate differences in pathogenicity and protective immunity between Norwegian sheep breeds.

\section{Acknowledgements}

The study is funded by Norwegian Research Council (Project number 173174), Animalia and Nortura SA.

\section{Author details}

${ }^{1}$ Norwegian School of Veterinary Science, Department of Production Animal Clinical Sciences, Sandnes, Norway. ${ }^{2}$ Bioforsk, Norwegian Institute for Agricultural and Environmental Research, Organic Food and Farming Division, Tingvoll, Norway. ${ }^{3}$ National Veterinary Institute, Uppsala, Sweden. ${ }^{4}$ Nofima Marin, Ås, Norway.

\section{Authors' contributions}

SS, LS, IO and HS have designed the experimental study. SS performed the experimental study, carried out the statistical analysis and drafted the manuscript. EGG carried out the molecular genetic analysis. KS performed the serology. All authors read and approved the final manuscript.

\section{Competing interests}

The authors declare that they have no competing interests.

Received: 19 November 2010 Accepted: 11 February 2011 Published: 11 February 2011

\section{References}

1. Foley JE, Foley P, Jecker M, Swift PK, Madigan JE: Granulocytic ehrlichiosis and tick infestation in mountain lions in California. J Wild Dis 1999, 35:703-709.

2. Foggie A: Studies on the infectious agent of tick-borne fever in sheep. $J$ Pathol Bacteriol 1951, 63:1-15.

3. Øverås J, Lund A, Ulvund MJ, Waldeland H: Tick-borne fever as a possible predisposing factor in septicaemic pasteurellosis in lambs. Vet Rec 1993, 133:398.

4. Stuen S: Tick-borne fever (TBF) and secondary infections in sheep. In Rickettsiae and rickettsial diseases. Edited by: Kazár J, Toman R Veda. Bratislava; 1996:347-349.

5. Jamieson S: Tick-borne fever as a cause of abortion in sheep - Part II. Vet Rec 1950, 62:468-470.

6. Tuomi J: Studies in epidemiology of bovine of tick-borne fever in Finland and a clinical description of field cases. Ann Med Exp Biol Fenn 1966, 44(Suppl. No. 6):1-62.

7. Watson WA: Infertility in the ram associated with tick-borne fever infection. Vet Rec 1964, 76:1131-1136.

8. Stuen S: Anaplasma phagocytophilum (formerly Ehrlichia phagocytophila) infection in sheep and wild ruminants in Norway. A study on clinical 
manifestation, distribution and persistence. Dr Philosophiae thesis Norwegian School of Veterinary Science, Oslo; 2003.

9. Stuen S, Bergström K: Serological investigation of granulocytic Ehrlichia infection in sheep in Norway. Acta Vet Scand 2001, 42:331-338.

10. Stuen S, Bergström K, Petrovec M, Van de Pol I, Schouls LM: Differences in clinical manifestations and hematological and serological responses after experimental infection with genetic variants of Anaplasma phagocytophilum in sheep. Clin Diagn Lab Immunol 2003, 10:692-695.

11. Stuen S, Van de Pol I, Bergström K, Schouls LM: Identification of Ehrlichia phagocytophila variants in blood from sheep in Norway. I Clin Microbiol 2002, 40:3192-3197.

12. Austrheim G, Asheim LJ, Bjarnason G, Feilberg J, Fosaa AM, Holand O, Hoegh K, Jonsdottir IS, Magnusson B, Mortensen LE, Mysterud A, Olsen E, Skonhoft A, Steinheim G, Torhallsdottir AG: Sheep grazing in the NorthAtlantic region - A long term perspective on managment, resource economy and ecology. Rapport zoologisk serie (NTNU); 2008, 3.

13. Scott GR: Tick-associated infections. In Diseases of Sheep. 1 edition. Edited by: Martin WB, Aitken ID. Oxford: Blackwell Scientific Publications; 1983:209-213.

14. Woldehiwet Z: The effects of tick-borne fever on some functions of polymorphonuclear cells of sheep. J Comp Pathol 1987, 97:481-485.

15. Granquist EG, Bårdsen K, Bergström K, Stuen S: Variant- and individual dependent nature of persistent Anaplasma phagocytophilum infection. Acta Vet Scand 2010, 52:25.

16. Artursson K, Gunnarsson A, Wikström UB, Olsson Engvall E: A serological and clinical follow-up in horses with confirmed equine granulocytic ehrlichiosis. Equine Vet J 1999, 31:473-477.

17. Dumler JS, Asanovich KM, Bakken JS, Richter P, Kimsey R, Madigan JE: Serologic cross-reaction among Ehrlichia equi, Ehrlichia phagocytophila and human granulocytic Ehrlichia. J Clin Microbiol 1995, 33:1098-1103.

18. Tapio M, Tapio I, Grislis Z, Holm E, Jeppsson S, Kantanene J, Miceikiene I, Olsaker I, Viinalass H, Eythorsdottir E: Native breeds demonstrate high contributions to the molecular variation in northern European sheep. Mol Ecol 2005, 14:3951-3963.

19. Rikihisa Y: The tribe Ehrlichieae and ehrlichial diseases. Clin Microbiol Rev 1991, 4:286-308.

20. Lin M, Rikihisa Y: Ehrlichia chaffeensis and Anaplasma phagocytophilum lack genes for lipid A biosynthesis and incorporate cholesterol for their survival. Infect Immun 2003, 71:5324-31.

21. Stuen S, Artursson K: Effects of the dose of Ehrlichia phagocytophila on the severity of experimental infections in lambs. Vet Rec 2000 146:669-672.

22. Stuen S, Hardeng F, Larsen HJ: Resistance to tick-borne fever in young lambs. Res Vet Sci 1992, 52:211-216.

23. Stuen S: Tick-borne fever in sheep. A clinical and immunological study. Dr Scientarium thesis Norwegian School of Veterinary Science, Oslo; 1990.

24. Stamp JT, Watt JA: Tick-borne fever as a cause of abortion in sheep Part I. Vet Rec 1950, 62:465-468

25. Woldehivet Z, Scott GR: Immunological studies on tick-borne fever in sheep. I Comp Pathol 1982, 92:457-467.

26. Woldehiwet Z, Scott GR: Tick-borne (pasture) fever. In Rickettsial and Chlamydial Diseases of Domestic Animals. Edited by: Woldehiwet Z, Ristic M. Oxford: Pergamon Press; 1993:233-254.

27. Brodie TA, Holmes PH, Urquhart GM: Some aspects of tick-borne diseases of British sheep. Vet Rec 1986, 118:415-418.

28. Foggie A: The effects of tick-borne fever on the resistance of lambs to staphylococci. J Comp Pathol 1956, 66:278-285.

29. Foster WNM, Cameron AE: Observations on the functional integrity of neutrophil leucocytes infected with tick-borne fever. J Comp Pathol 1970, 80:487-491.

30. Stuen S, Nevland S, Moum T: Fatal cases of tick-borne fever (TBF) in sheep caused by several 16S rRNA gene variants of Anaplasma phagocytophilum. Ann NY Acad Sci 2003, 990:433-434.

doi:10.1186/1751-0147-53-8

Cite this article as: Stuen et al:: A comparative study of clinical manifestations, haematological and serological responses after experimental infection with Anaplasma phagocytophilum in two Norwegian sheep breeds. Acta Veterinaria Scandinavica 2011 53:8.

\section{Submit your next manuscript to BioMed Central and take full advantage of:}

- Convenient online submission

- Thorough peer review

- No space constraints or color figure charges

- Immediate publication on acceptance

- Inclusion in PubMed, CAS, Scopus and Google Scholar

- Research which is freely available for redistribution 